\title{
Can Technology Support Democracy?
}

\author{
DOUGLAS SCHULER, The Evergreen State College, The Public Sphere Project
}

\begin{abstract}
The utopian optimism about democracy and the internet has given way to disillusionment. At the same time, given the complexity of today's wicked problems, the need for democracy is critical. Unfortunately democracy is under attack around the world, and there are ominous signs of its retreat. How does democracy fare when digital technology is added to the picture? Weaving technology and democracy together is risky, and technologists who begin any digital project with the conviction that technology can and will solve "problems" of democracy are likely to be disappointed. Technology can be a boon to democracy if it is informed technology. The goal in writing this essay was to encourage people to help develop and cultivate a rich democratic sphere. Democracy has great potential that it rarely achieves. It is radical, critical, complex, and fragile. It takes different forms in different contexts. These forms are complex and the solutionism promoted by the computer industry and others is not appropriate in the case of democracies. The primary aim of technology in the service of democracy is not merely to make it easier or more convenient but to improve society's civic intelligence, its ability to address the problems it faces effectively and equitably.
\end{abstract}

CCS Concepts: • Human-centered computing $\rightarrow$ Collaborative and social computing; • Applied computing $\rightarrow$ Egovernment; Voting / election technologies;

Additional Key Words and Phrases: Democracy, civic intelligence, digital technology, technological threats, history of computing

ACM Reference format:

Douglas Schuler. 2020. Can Technology Support Democracy? Digit. Gov.: Res. Pract. 1, 1, Article 3 (January 2020 ), 14 pages. https://doi.org/10.1145/3352462

\section{HISTORICAL DREAMS AND CONTEMPORARY NIGHTMARES}

In the summer of 1991, the cover of the Whole Earth Review, the quarterly offspring of the Whole Earth Catalog, sported a psychedelic and apparently jacked-in Benjamin Franklin peering out from a computer screen. The topic, "electronic democracy," was assumed by some to be an inevitable outgrowth of the internet, which was still largely unknown and inaccessible to most people. In fact it was to be another four years before the internet was made available to the public and was launched on its course of domination by state and commercial interests. Taxpayers of the United States had been funding its development for years, yet there had been little to no prior public discussion about how the internet might help meet the country's democratic needs. (One exception was Reference [1]). And the concept of electronic democracy, which although it had been making regular occurrences in the popular press for a time, vanished upon the arrival of the more pertinent concept of e-commerce.

Author's address: D. Schuler, The Evergreen State College, The Public Sphere Project, 2202 N. 41st Street, Seattle, WA 98103, US; email: douglas@publicsphereproject.org.

Permission to make digital or hard copies of all or part of this work for personal or classroom use is granted without fee provided that copies are not made or distributed for profit or commercial advantage and that copies bear this notice and the full citation on the first page. Copyrights for components of this work owned by others than the author(s) must be honored. Abstracting with credit is permitted. To copy otherwise, or republish, to post on servers or to redistribute to lists, requires prior specific permission and/or a fee. Request permissions from permissions@acm.org.

(C) 2020 Copyright held by the owner/author(s). Publication rights licensed to ACM.

2639-0175/2020/01-ART3 $\$ 15.00$

https://doi.org/10.1145/3352462

Digital Government: Research and Practice, Vol. 1, No. 1, Article 3. Publication date: January 2020. 
The special section was edited by internet pioneer Howard Rheingold. It included articles on CompuMentor, which provided computer assistance of all kinds to non-profit organizations, and Earthtrust, an early adopter of email for environmental activism. There were also articles on diverse approaches to computer-mediated communications such as electronic town meetings, global commons, electronic city halls, and others. In his introduction to the section, Rheingold suggested digital communication might become the "great equalizer," an unfortunate metaphor based on the Colt .45 pistol that purportedly leveled the playing field between rivals in America's old west [2]. However naive that may seem now, the section was visionary while also providing practical resources. Missing or at least underrepresented were the more ominous aspects of computing, such as those that Computer Professionals for Social Responsibility (CPSR) helped bring into public view such as the Strategic Computing Initiative whose aim was to use artificial intelligence (AI) to help automate warfare.

Unlike many, perhaps a majority, of the people who discussed these issues in somewhat public forums and had vague premonitions that the internet was probably going to be something quite earth shattering, I differed in three somewhat fundamental ways. The first was that I did not think government was going to go away-nor even that it should go away. I confess that I harbored this unpopular belief even though I found myself very frequently-or nearly always-differing from the actions that the government undertook in my name, too often at the direction of large corporations, vestigial cultural prejudices, militarism, or generalized animosity toward the poor. The second was that I was not actually optimistic about the future of the internet. I was familiar with the fates of other communication innovations that the hackers of bygone eras had championed which subsequently had been captured by powerful interests. But I would not characterize myself as pessimistic, either. I was actually (and still am) fairly militant in my belief in meliorism, the idea that things can get better-if people are willing to work for them. This places me teetering between the abyss of pessimism and the pie-in-the-sky of optimism, thus allowing people on both extremes to chide me for not really understanding what is going on. Finally, I did not believe that the internet was magic, insofar as it had its own spirit-to route around censorship, for example-and that it was destined to bring joy and probably even enlightenment to all whom it touched, that it was inviolate and resolute, and would refuse to succumb to the siren songs of the dollar.

We have subsequently learned that digital communications, like the media that predated it, was (and is) ideologically malleable. It could be commercialized and it could be weaponized. Many people have learned after this last round of technological development and deployment that the internet does not have a bias toward serving humanity. And many others have still not received that memo. And the utopian and solutionist rhetoric from the computing industry shows no signs of tempering its promises.

Because I subscribed to a meliorist viewpoint I have been involved in a number of projects related to civic tech. Working with lots of volunteers I organized a dozen or so Directions and Implications of Advanced Computing (DIAC) conferences for CPSR which provided a big tent for community, democratic, and critical considerations of computing. Among other issues, the conferences brought up issues that were mostly being ignored. The theme of DIAC 1994, for example, was "Developing an Equitable and Open Information Infrastructure," which contained articles on the "information superhighway," economics and gender issues, non-profits, post-modern technology, media regulation, and access for the poor [3].

The DIAC work indirectly led to the development of the Seattle Community Network ${ }^{1}$ which was part of a larger movement worldwide [4]. Working with the Seattle Public Library, we provided web space and thousands of email accounts at no cost before Hotmail, Gmail, and the rest had sprouted up. And the principles that we had adopted early in the project made it clear that we would not surveil our users. Needless to say, these projects did not thrive in the ways we would have liked them to. A combination of factors stood in the way: the tidal wave of commercial investment and attention and the lack of long-range collaborative vision or the will to fight for our principles. Frankly speaking, the memes won: The future unfolded the way it did because the ideas that were dominant at that time prevented us from creating durable non-commercial alternatives.

\footnotetext{
${ }^{1}$ www.scn.org.

Digital Government: Research and Practice, Vol. 1, No. 1, Article 3. Publication date: January 2020.
} 
On a larger scale, the internet as a whole proved to be quite amenable to large-scale non-democratic enterprises. Knowledge is power, it is said, but there is an important, rarely mentioned qualifier: The relationship is only true if one has the power to employ the knowledge. If somebody wants to do a lot of damage these days, then they will definitely need to enlist technology. And, as with the case of the proverbial barn that is easier to burn down than to build, democracies are more easily degraded than improved-or so it seems.

So while I was actually expecting the type of corporate takeover that has always followed the advent of new media I was stunned by the intensity of the onslaught that I had believed (knew?) would happen. And to be honest, I did not foresee the insidious fake news that seems to hit many of our citizens precisely where they reside subconsciously. I had also not adequately foreseen the massive corporate intrusion into every conceivable aspect of our personal lives (with presumably more on the way) and the subsequent data monetization that the new tech had made possible.

Fewer than 30 years after the Whole Earth Review section on electronic democracy, the January 2019 issue of the fournal of Democracy reveals how digital technology, generally in the thrall of authoritarian governments or intrusive corporations, rather than being the harbinger of enhanced democracy, actually provides the secret ingredient behind major attacks on democracy worldwide. "The Road to Digital Unfreedom" section contains articles that describe four trends in computing that are actively degrading democracy.

In one of the articles, Deibert [5] presents "three painful truths about social media" in which he points out:

1) that the social-media business model is based on deep and relentless surveillance of consumers' personal data in order to target advertisements; 2) that we permit this staggering level of surveillance willingly, if not altogether wittingly; and 3) that social media are far from incompatible with authoritarianism, and indeed are proving to be among its most effective enablers.

In China, the world's most populous country, "PRC [Peoples Republic of China] authorities are working to integrate information from a wide array of sources into a nationwide Social Credit System (SCS) that would assess the conduct of every person in the country, an innovation worthy of George Orwell's Nineteen EightyFour" [6].

And around the world, the much-touted capabilities of AI and deep learning are demonstrating some of the power that they can help enable which, unfortunately, is a far cry from the sanguine assurances in the media. For example, according to Feldstein [7], "Around the world, AI systems are showing their potential for abetting repressive regimes and upending the relationship between citizen and state, thereby accelerating a global resurgence of authoritarianism."

Unfortunately as the internet is being shaped into a conduit for malevolence the world is faced with staggeringly wicked problems (such as climate change, environmental destruction, war, oppression, and poverty) that demand some type of informed response. But how that is conceived and what forms it takes necessarily would need to be vastly different than what exists now if it is to be even remotely successful in addressing these problems.

\section{WHAT IS DEMOCRACY?}

While "democracy" has a definition in the dictionary, in the world outside of dictionaries it takes different forms. For our purposes it makes sense to think beyond something that matches a dictionary definition or abides by specific formal rules. We need to think about democracy in terms of ideals that it could aspire toward as well as realities, the forms democracy actually takes in the real world where they fall short of those ideals. These various versions of democracies reveal a variety of traits that tend to be pertinent in all the cases we see. They can help us think about how democracy is enacted or institutionalized (including the introduction of technology) and what challenges and opportunities are relevant. Some of these traits remind us of our worst selves and some give us hope.

Digital Government: Research and Practice, Vol. 1, No. 1, Article 3. Publication date: January 2020. 


\subsection{Democratic Aspirations}

Democracy is an approach to governance in which people meaningfully and intentionally participate in the decisions that affect them and other members of the group. This means participating in public problem-solving and checking power, both of which remain necessary with or without technological integration. Ideally democracies provide equal opportunities to everybody and they are not dominated by small numbers of powerful people. Paradoxically, they should not be dominated by large numbers of less-powerful people, either-the so-called tyranny of the majority in which people use their majority status to oppress and marginalize the minority. In a democratic country, governance means that while being respectful of other institutions such as organized religion, labor unions, or corporations, the sovereign body is the government and this is constituted $b y$, for, and with the people-not at the behest of other institutions.

Democracy is different than a natural resource in that it is designed, maintained, and used consciously and subconsciously by people. But looking at democracy as a commons is a fruitful analogy that does nothing to distort the idea of democracy. On the contrary it suggests that attention, vigilance, and maintenance are critical if the democracy is to deliver the results that it should. When seen as a commons or shared resource, democracy can viewed as something that all can contribute to and all can draw from. And, if under threat, a resilient democracy has defenses it can rely on to prevail in situations where a weak or immature democracy might fail [8]. Hélène Landemore makes the case that democracies are more likely to develop good decisions than other forms of governance because of democratic reason which emerges through democratic processes [9]. Through drawing on concepts from cognitive science and from ideas about collective intelligence such as "crowd-sourcing," Landemore describes democratic reason from which collective bodies can draw and develop ideas, shared ideals, and aspirations.

A democracy should employ reason and compassion when making its decisions, although in the real world this is often not the case. Ideally, the decisions that emanate from the democratic processes would be good decisions, meaning that they are effective in addressing significant issues while being equitable to the people who are being affected. The term civic intelligence describes this capability within a country, a region, or any collectivity [10]. It is this capability that dictates the quality of governance (in the broad sense) within any group, and groups that make good decisions can be said to have better civic intelligence than those who do not. We call this phenomenon civic intelligence, because it describes the characteristics that are needed for groups to make good decisions: It perceives both challenges and opportunities, current and impending; it has (or will find) the requisite knowledge about the issues and the resources it can draw from; it improves its own processes; and it incorporates people from all walks of life into decision-making and responsibility for the resources and challenges that are appropriate for the group. Civic intelligence incorporates all the features that would characterize intelligence in an individual, including perceiving, learning, negotiating, decision-making, remembering, and reasoning. Civic intelligence could be thought of as an updated version of civics that is more expansive in that it includes a much broader range of civic activities than how bills are passed. It builds on recent work in cognitive science and distributed intelligence and foregrounds the idea of public problem-solving.

Democracy, in theory, determines how people govern themselves now and in the future. And because technology is burrowing ever deeper and ever faster into the fabric of our lives, the environment, and, ultimately, what we perceive as reality, democracy is increasingly tasked with the necessity of looking ahead into an uncertain future. Democracy should anticipate forthcoming issues-not merely react to current ones-and provide what Habermas calls a "warning system with sensors" [11]; it should be smart (it must learn), and it should be fair. It also should be resilient. It should respond appropriately when needed, and it should bounce back when attacked.

\subsection{Democratic Realities}

Looking at democracy solely as an abstraction or as something that is described in its entirety by a dictionary definition ignores many of the ideas and issues that we need to think about when working in real-world

Digital Government: Research and Practice, Vol. 1, No. 1, Article 3. Publication date: January 2020. 
situations. The abstraction helps us see the broad concept, but looking at the ways it plays out in various contexts is needed to see what we are really working with. We need to operationalize the topic to some degree and look at its constituent pieces to understand it at a meaningful level. This knowledge will be useful as we propose or contemplate changes, experiment with various approaches, or evaluate outcomes. And for each version of democracy that we see (including the ones that are deficient or degraded) critical questions can be asked, ones whose answers can be found empirically not through contemplating dictionary definitions or Platonic ideals. How is democracy manifested in various contexts? How did it come to be in the form it is? What roles do people, institutions, and cultural values play? What roles do technological interventions and mediations currently play? What roles might they play in the future? And in addition to thinking about how that things came to be and how they might be different, we need to think of the why something happened or did not happen or why we think that something else should happen.

2.2.1 Democracy That Works at All Well Is a Rare Commodity. A democracy that performs the basic functions of "promoting the common welfare" as well as tamping down corruption at the top is relatively rare (more on this below). "Working" does not simply mean the act of holding regular elections where people are given a handful of boxes to check (which might satisfy a dictionary definition). At the same time the state of a democracy is also fragile-it can degrade and it can give way to fascism and totalitarianism. This fact supports the analogy that democracy can be thought of as a type of resource, one that will depend on wise stewardship if it to perform its job well.

2.2.2 Democracy Is Richly Textured and Has Multiple Layers. Democracy, as with many other commonly used concepts, is not a trivial or one-dimensional concept. It is not the case that a country (or other collective entity) either is or is not a democracy. And using a simplistic and nonexistent conception of democracy as the basis for reform or technological development is likely to make matters worse. Equating democracy, for example, with the "final" act of voting dangerously trivializes the idea of democracy. For one thing, voting is not a one-time affair but happens all the time at all levels of government (sometimes to reverse a decision that had been determined through prior voting). Equating democracy in this way also ignores the vital deliberative processes through which the "minority becomes the majority" that are fundamental to democracy. And democracy has multiple layers-from the development of individual and public opinion to policy development to collective action and voting. It also includes consideration of the mass media and, as of late, social media. It raises a variety of questions and concerns: Who participates and on what issues? How is public opinion developed? What formal avenues? What informal ones? How are the values of democracy institutionalized? What avenues of redress exist to question or reconsider an action? What protections do people have to mediate illegitimate uses of power? When are processes outside the formal structures of democracy such as demonstrations, protests, and civil disobedience warranted?

2.2.3 Democracy Requires Citizens and Civic Culture and Infrastructure. Many people mistake what theynotice for the whole thing when in reality, democracy is more like an iceberg where much of the social and material "machinery" that makes it work is submerged below the surface. Citizens are the actors in a democracy, but they would be unable to participate at all without sufficient culture and infrastructure. But when we refer to "citizens," we are not speaking about who is legally sanctioned to vote, run for office, or have other rights, but citizens in the sense that they are prepared for participation in democracy. Citizens need the motivation, deliberative skills, information, and other resources to participate meaningfully. And in the interests of developing a strong civic culture, there should be opportunities to advance all of these. We are cognizant of the tendency for the idea of citizen preparedness to be abused in order to diminish the participation of certain groups. Citizenship tests, for example, were developed in the southeastern United States expressly to deny voting rights to African Americans. The focus on preparedness is intended to highlight the responsibility of a democratic government to help furnish whatever services and resources are needed to prepare citizens for active, effective, and intelligent engagement. 
If some group does not have any specific civic enabling skill or resource, the approach must be to help strengthen that civic enabler-not to restrict the participation of that group.

A collectivity with strong civic intelligence treats all of its citizens well. This is particularly important in the field of education. Viable democratic societies require quality education for all their inhabitants. Thinking about civic intelligence means thinking about education from a slightly different perspective-as does thinking about democracy with more emphasis on civic intelligence, strong democracy, civic problem-solving, and so on, than as a set of algorithmic procedures in the absence of learning, education, norms, or values. Learning about civics should include mistakes that had been made, not be a dogmatic exercise where a country's history is only remembered as one of historic greatness or that the founders were all saints. And holding the founding documents in a state of fetishistic reverence invites misuse, especially by people who claim to hold the sole key to precise interpretation.

Finally, especially when considering democracy and technology, we need to remember that democracy requires material infrastructure and this infrastructure requires maintenance as any other. Even in the case of voting, a vital seemingly trivial (and, hence, easily implemented via technology) element of the process, there needs to be resource expenditure, voter guides, candidate forums, limits on campaign contributions, independent election monitors, redistricting boards, and so on. Also, of course, since voting is such a vital element, tampering with any aspect of the process represents an irresistible opportunity to subvert the democratic process.

2.2.4 Democracy Is Not Inevitable. Unfortunately, many of the nostrums related to democracy that have been presented as immutable truths in academic circles turned out to be vague generalizations that in no way could be supported empirically. Just to note one in passing, the idea that capitalism necessarily leads to democracy seems to be wishful thinking, as Singapore has demonstrated. This was followed by China, their much larger neighbor, that has apparently adopted capitalism with Chinese characteristics. The presumption that democracy would naturally arise from the ashes of the decimated communist political and economic infrastructure of the USSR also falls in that category.

When looking at the current state of the 91 newly formed or democracies of the "third-wave" of democratization that started in 1974 that looked so hopeful not so long ago, there were "breakdowns or stagnations" in 62 of them [6]. Also, according to the Economist Intelligence Unit [12], "a new study has found that 49.3 percent of the world's population lives in some form of democracy while only 4.5 percent of people live in full democracies." The research, which was conducted across 165 countries, "found that 89 countries experienced a fall in their democracy score compared to 2016 with only 27 improving and the rest stagnating."

At the same time, when people in established democracies lose faith in their system, they are presumably less likely to defend them or participate in them. Looking at long-term surveys of attitudes in established (or "consolidated") democracies in North America and Western Europe [13], researchers found that citizens "have not only grown more critical of their political leaders" but "they have also become more cynical about the value of democracy as a political system, less hopeful that anything they do might influence public policy, and more willing to express support for authoritarian alternatives." They conclude that, "the crisis of democratic legitimacy extends across a much wider set of indicators than previously appreciated." It is a depressing, but not necessarily irreversible, reality of this time that many of the world's most populous and powerful countries have demonstrated increasingly authoritarian behavior.

2.2.5 Democracy Is Subject to Abuse of All Types. Much of the abuse is done at the behest of the powerful, the wielders of far-reaching levers, who, because of their small numbers, must enlist less-powerful people in pursuit of their ideological and other goals. It also often means employing non-democratic means such as gerrymandering, media control, banning of opposition political parties, corruption, political rhetoric with violent overtones, and scapegoating and suppression of minority groups. At the same time, a democracy where all have equal voices does not exist. And, paradoxically, democracies can also be degraded by people who are not powerful. Some people believe (with some accuracy) that the political system does not care about them so they choose

Digital Government: Research and Practice, Vol. 1, No. 1, Article 3. Publication date: January 2020. 
not to participate. There are also some who think that their inattentiveness to the state of democracy is a well thought-out, principled stand. Others perceive that this attitude is socially advantageous for them in terms of their peer group: They are above it all, aloof and untouched by the inherent dirt in politics. Unfortunately it is difficult to get motivated when the problem does not seem to affect one personally or if one believes that a bad situation will resolve itself one way or the other, regardless of anything that anybody can do. The truth is that democracy requires participation from a wide cross-section of people if it to function at all satisfactorily. Apathy breeds apathy, and apathy silently erodes democracy.

Hate speech and oppression can effectively paralyze any hope for progress via democratic decision-making, and thus promoting them can be a relatively inexpensive way for unethical leaders to maintain the status quoand their power. Some people are particularly susceptible to this, and that is one place in which an updated civics education that includes critical reasoning could theoretically be very useful. Countries that embrace authoritarianism are more likely to do violence to their own people (generally the poor, immigrants, sexual minorities, religious minorities, etc.) and are more likely to blame any problems that the country may face on those people-and on enemies beyond their borders. Thus, there would be no problems at all in Russia without the west, the United States in particular. And in the eyes of some in the United States, all would be just great if only a wall could be erected along the border with Mexico. Thus more energy is expended demonizing the other than addressing actual problems. In other words, while the powers that be are spending their time raising hatred and fear, the problems that their country faces continue to deteriorate thanks to their misgovernance.

The study of democracy often seems to discount the magnitude of the forces that wish to subvert it. Yet citizens would presumably be better prepared to deflect those forces if they were more schooled about how it plays out in the real world. Democracy is always enacted within an environment with bad actors, people who are willing to subvert the system to gain the power they want. And while the psychological lapses and reasoning defects in individuals are legion the industrial strength propagation of ignorance throughout society is truly a boon for anti-democratic forces. Indeed, the new research focus on agnotology, which studies "... the conscious, unconscious, and structural production of ignorance, its diverse causes and conformations, whether brought about by neglect, forgetfulness, myopia, extinction, secrecy, or suppression" [14], hopefully is now getting the attention it deserves. The long-term campaign by US-based big tobacco corporations to deceive and confuse the American public about the health effects of smoking is the one of the best-documented examples of agnotology. It is instructive to note that the same public relations firm that orchestrated the smoking obfuscation campaign has been directing its attention to sowing confusion in relation to climate change [15]. Needless to say, this high level of deception makes the job of self-governance more difficult.

2.2.6 Democracy Is More About Processes than It Is About Outcomes. Having said that, there is value in looking at the outcomes of the processes as well as the quality of the processes. In fact, it is possible to use proxy measures to characterize the overall quality of a democracy by examining features that both spawn the civic culture and are a product of a civic culture. The following draft list of measures helps show what a coherent rubric of outcomes for a given town, region, country, and so on, might look like:

1. Responsive, transparent, honest, well-informed government

2. Shared and diverse knowledge

3. Social (political, educational, cultural) engagement

4. Social capital and other citizen capabilities and skills

5. Health and well-being

6. Opportunities-economic and other

7. Relative equality of inhabitants

8. Good neighborliness in relation to entities outside its own boundaries (does not take more than it needs; or export its problems...)

9. Availability of open and diverse information and communication systems

Digital Government: Research and Practice, Vol. 1, No. 1, Article 3. Publication date: January 2020. 
Measures like this could also reveal trends. If, for example, these proxy measures were to remain at low levels for a significant amount of time, it might help reveal a superficial democracy in which elections are regularly held-and perhaps even highly contested-but nothing seems to happen or change as a result. There seems to be some evidence that this is the case in the United States in relation to proxy measure 7: relative equality. Economic reports show that "since the early 1970s, the hourly inflation-adjusted wages received by the typical worker have barely risen, growing only $0.2 \%$ per year" [16], while the income of the top $1 \%$ has doubled during the same time period. And, currently, "an estimated 43.5 percent of the total U.S. population (140 million people) are either poor or low-income" ${ }^{2}$. A Princeton study focusing on legislation and public opinion also highlights proxy measurement 1, responsive government, in which the government of the United States receives low marks [17]. One main finding based on analysis of 1,179 policy issues is that "economic elites and organized groups representing business interests have substantial independent impacts on U.S. government policy, while average citizens and mass-based interest groups have little or no independent influence." In other words, economic elites and their associations appeared to be the sole determinant of legislative outcomes.

2.2.7 Finally, Democracy, Even If Somewhat Thin, May Reveal Resilience When Threatened. At the same time democracy can degrade, it also can be unexpectedly resilient, as we are now seeing in the United States. There has been an upswing in civil society organizations who focus on transparency, human rights, civil rights, health care, education, and other related themes, which is probably due to the unexpected and unprecedented actions at the federal level that are being perceived by many people as major threats to democracy. Resiliency is a good thing in a democratic system, but it may be difficult to tell when it is democratic resilience and when it is a mechanism for maintaining the status quo, which is the basis of the "deep state" critique that is being leveled at the current civil society activism.

\section{THINKING ABOUT DIGITAL SYSTEMS AND DEMOCRACY}

Whether beneficial or not, digital systems are employed now and will be employed in the future as integrated elements of democratic systems worldwide. What do we need to know to engage meaningfully in this field? Typically people think about the two perspectives as being more or less like fish and fowl or oil and water. They are not necessarily the same thing of course, and quite possibly they do not mix well. However, as was discussed above, citizens need civic culture and they need civic infrastructure-both of which are potentially significant areas for digital systems and democracy. It should be noted that the researchers and practitioners of the two perspectives are likely to have distinct mindsets, assumptions, and ways of doing things. Both groups, of course, should know something about both perspectives. Nobody knows everything about their own field-if they do, then their field is too small. Both sides should respect the other point of view-but should not mistake slogans for facts. And the collaboration of social scientists and technologists, while a step in the right direction, is still deficient without the presence of citizens, the "users" of the democratic systems, who by all rights should be involved in any integration of technology into democratic systems-including its design.

We might well note here that this territory has hidden risks. It is redundant to say this again, but the new digital technology has not proved to be a boon for democracy. Ironically, this unfortunate turn of events opens up new opportunities for digitally oriented researchers and practitioners: how to limit, tame, bypass, expose, police, or replace the various forces that are degrading democracy. These actions, indeed, could be considered dangerous in ways that more orthodox academics may never experience since the forces that are degrading democracy often have much in the way of resources and few restraints, moral or otherwise, on their behaviors. Moreover, because democracy is not merely a set of algorithms, the opportunities for integration at many levels are limitless, including many that pay far less well than working for a tech titan. Working with community groups to identify challenges and opportunities related to computing and democracy might be the "best" use

\footnotetext{
${ }^{2}$ inequality.org/facts/income-inequality/.
}

Digital Government: Research and Practice, Vol. 1, No. 1, Article 3. Publication date: January 2020. 
of one's time if money was not an issue. While being less appealing to some and probably harder to support financially, especially over the long haul, this type of effort is one aspect of a broad democratizing push. And, sadly, some enterprises, while paying more, could also be playing, possibly indirectly, into the hands of enemies of democracy, both large and small.

\subsection{It Is Difficult to Cleanly Define the Boundaries Related to Digital Systems and Democracy, and It Is Probably Best Not to Police Them Too Assiduously}

Looking at digital systems from the standpoint of democracy is inherently interdisciplinary. Thus, tight disciplinary restraints could hinder the cognitive development this enterprise is trying to promote. Moreover, even the basic boundaries between democratic behavior and non-democratic behavior, democracies and non-democracies, and digital systems and non-digital systems are murky.

There is no clear line between what constitutes democratic behavior and other behavior. Certainly it would be an error to mistake the formal apparatus of democracy for the whole of democracy. An election or legislative assembly certainly falls within the formal category, but I would argue that the Occupy Movement, writing a letter to an elected official, and even a conversation between two friends about their rights, their feelings about government, or what constitutes the "good life" are all valid elements to consider in relation to democratic systems and, of course, to this journal. Any activity that ultimately influences public opinion and decision-making in some way is part of democracy. As for the distinction between democratic countries and non-democratic ones, it is true that some countries are more democratic than others. What is less true is that the less-democratic countries should be omitted from this discussion. For one thing, it seems that all countries incorporate some types of input from people into their decision-making-even if the citizens do not know it is happening. Countries (and other political entities) change over time in terms of the quality of their democracy. For that reason, studying non-democratic countries is important, because they might ultimately become more democratic-possibly, even, because of the work published in this journal. If, for example, we only looked at "full democracies," then we would only be concerned with $4.5 \%$ of the people in the world [12]. That represents a large number of people but would exclude the vast majority of the people in the world, even those living in countries with some degree of citizen participation.

And, finally, I would argue that a focus on digital democracy is fine, but in no way should it implicitly assert that all of the democratic behavior that people do off-line does not exist or that it is not relevant. Digital and nondigital democratic behavior happens every day and often interact. People engage in both quite seamlessly, and our practice would be diminished if the digital focus denied a significant part of an important societal dynamic because it was not mediated via technology.

I hate to reprise the old metaphor about the boy and the hammer, but it hits the nail on the head perfectly. In spite of what might come into the mind of a software engineer, democracy is not a technical problem. Democracy employs algorithms, protocols, quorums, and the like, but democracy is not defined strictly as a set of welldefined algorithms. (And it is not all about voting and "majority rules.") But technology plays a role sometimes in surprising ways-and has for a very long time. According to both Aristotle and Aristophanes, water clocks were in common use in legal courts around $430 \mathrm{BCE}$ as timers to limit the length of speeches [18].

Democracy is also somewhat inscrutable, and herein lies the danger posed by computer scientists and their employers: This unknowable nature cannot be simply reduced to algorithms. This is not to say that the concepts and elements of democracy cannot be understood at all, only that democracy cannot be seen as simply (strictly?) algorithmic. Capturing the algorithms, institutionalizing them in code, and running the show with no fuss or bother to the average citizen is not a sensible or worthwhile goal. It assumes that citizens are not prepared adequately to participate, and it sets out to achieve that unwanted state.

Another danger involves setting up a somewhat imprecise (if not outright dubious) task such as developing a tool for identifying high school students who are likely to commit crimes. What would people do with such a

Digital Government: Research and Practice, Vol. 1, No. 1, Article 3. Publication date: January 2020. 
tool? Give the potential miscreants counseling and help them with the problems they may be facing? Or perhaps tracking them surreptitiously and keeping private records on them? Or perhaps politicians would like to know what the public "thinks" at any given time. One school of thought would have it that in a democracy, the policy at any given time should simply reflect this will of the people that is present at that time. With this as the primary operating procedure, one could determine what the policy ought to be via some fancy tool or perhaps AI-directed big data analysis of Google search terms or conversations that people had with friends or family, without any awareness that their conversations were being taped for future political mining. And then there is always the nagging question of who will use these data and for what purpose.

Many companies still market their software systems as "solutions" to complex problems, trading on people's general lack of technical understanding of computers, including the limits to what they can or cannot accomplish. The computing field is rife with memes and universal declarations that quickly dissolve with the arrival of new ones. AI and deep learning, according to the tech companies, are pretty much good for whatever ails you-at least this season. Sadly, some computer professionals seem to believe that democracy offers low-hanging fruit for technology development. Unfortunately, simplistic approaches can actually make matters worse. To this I would offer the following advice to everybody involved in technology and democracy: eschew solutionism. No one approach will or can solve or fix democracy. Unfortunately, solutionism seems to be part of the genetic makeup of the tech community-and hence of the consumers of tech products and services. After all, why settle for something that will merely improve something when you can get something that solves the problem once and for all. There is nothing wrong with making democracy easier or more convenient-but these are not the sole goals (if democracy has "goals"), nor are they desirable if the net result is dumbing down the citizenry. The sole point is not to make democracy easier to do but make democracy more vital and more responsive. (Although removing roadblocks such as gerrymandering, voter suppression, and so on, would help to make democracy more vital and more responsive.)

\subsection{Technology and Democracy May Be Working at Cross Purposes}

Given all of the above, it may actually be the case that technological development may continue to outpace any controls that are put upon it, to promote (or save) democracy, for example. Working in the field of democracy impels us to consider critical perspectives that are not necessarily present in other fields: namely the issues of concentrated power and general ignorance, the omnipresent enemies of democracy. These factors make it more problematic as part of a public problem addressing approach. At every step along the way in democratic decision-making there are opportunities for tech-enabled threats that can seriously disable democratic processes.

Focusing on democracy presents constraints on researchers and practitioners. For one thing, there are requirements related to this work that are not present in products whose potential merit is largely based on financial rewards. While the first line to be drawn could be called the "do no evil" point (more on this later), the other extreme might be "do the most good"-and anything in between might be acceptable. When it looked like the internet was a go, well-resourced entities such as corporations and national governments (and organized crime) wasted little time in colonizing the more-or-less virgin e-territory. The pace was breakneck and would-be civic developers, regulators, and critics found themselves outflanked and vastly outspent in the battle of the memes. And new technology, such as facial recognition software or next-generation brain-computer interfaces, that open up vast new opportunities for good-or for the truly evil-deserve the highest scrutiny. The people paying your wage to develop digital democratic systems may be part of the problem. Are the tools being developed strengthening the already powerful or weakening the already marginalized?

\section{TOWARD A RICHER DEMOCRACY}

The main reason for looking into these issues at all is to improve the way that we work together to address the problems that we are currently facing and expect to face soon enough. The magnitude and complexity of

Digital Government: Research and Practice, Vol. 1, No. 1, Article 3. Publication date: January 2020. 
these problems adds urgency to this need. Humankind and the other lives on the planet that are affected by our collective behavior are imperiled by rampant misuse of technology, yet in our quest to improve democracy (in the hopes of wiser outcomes) we are obliged to work with the technology to capitalize on the opportunities that we believe it provides. We are trying to repair the vehicle we are driving that is already racing at full throttle into a dangerous and uncertain future.

The responsibilities for improving democracy, our public problem-solving capabilities, our civic intelligence, fall on everybody on the planet. Shirking these responsibilities or presuming that the elites, the powerful, the government, or business will address these issues on our behalf would mean collective suicide. Allowing that to happen has probably always been a terrible idea, but it is particularly outrageous now given the state of the world and the abuses that those in power have already inflicted-and profited from. And although everybody has some responsibility for the present and the future the people working in this particular field-democracy and technology-must assume additional responsibility. This focus is one of the most critical: It is central to many of the major issues of our day. There are battles over the future of democracy and technology is at the center. As a force multiplier, we worry that technology seems to favor the non-democracies.

Today's circumstances argue for a rich type of democracy. Many people have been significant bearers of this message, but it was John Dewey who laid out the groundwork for thinking about democracy as the foundation for nearly everything that is important. He described how and why citizens in the United States (and presumably throughout the world) ought to be thinking together collaboratively as a type of "common faith" [19] that they will need to resolve their differences and address their pressing problems. More recently, Benjamin Barber presented important distinctions between strong democracy and thin democracy [20], and Xavier de Souza Briggs highlighted the importance of problem-solving and democracy based on cases from around the world [21]. Richard Sclove, writing in Democracy and Technology [22], built a strong case "that technological design and practice should be democratized."

Many agree that wicked problems are becoming more threatening and that our approaches to addressing them seem outmatched. But for all of the nightmarish implications, there are definitely glimmers of hope. Many people in civil society, academia, and government are working in the deliberation arena that focuses directly on public problem-solving. A recent article in Science by 20 scholars describes how the science of deliberation can help address the "crisis of democracy" [23]. The article provides empirical support for deliberative democracy in which citizens with proper preparation, engagement norms, and time can work together across various divides to develop decisions that are informed and mutually satisfactory. Over the past couple of decades, there have been thousands of experiments with various types of deliberative processes. These include "citizens' juries, citizen panels, deliberative forums and polls, consensus conferences, and citizens' assemblies" [23], and many others. One notable recent example was the Irish Constitutional Convention and subsequent Citizens' Assembly, which were convened to deliberate a variety of issues, including same-sex marriage and abortion. Other deliberative experiments have taken place around the world, including, for example, Australia, China, Colombia, Belgium, Northern Ireland, Bosnia Mongolia, Germany, Denmark, the EU, and Oregon and California in the U.S. Hélène Landemore's work on epistemic democracy [24] reveals that "psychological research shows that even if people are bad solitary reasoners, they can be good group problem-solvers" and that "individual reasoning can improve under the right social conditions." People working with a technological focus are working on approaches that encourage productive argumentation. Anna De Liddo stresses the critical importance of argumentation for democracy, which she separates from simply arguing and the necessity of working collaboratively with people who do not share the same background or worldviews [25]. Hence, she explores how comments that go beyond Facebook's "thumb's up" and Twitter's "heart" can encourage collaboration. The Science article concludes by saying that "because the importance of deliberative moments lies in what they can do for the system as a whole, there is a pressing need to bring them in from the margins and make them a more familiar part of standard political practice." The question of whether these systems can be integrated into democratic or public problem-solving processes and yield the results that we need fast enough is an urgent and open question.

Digital Government: Research and Practice, Vol. 1, No. 1, Article 3. Publication date: January 2020. 
One of the most important chores related to looking at democracy and technology is having extensive conversations with people outside one's own niche. Democracy is a sprawling and inclusive topic that can be informed from many points of view. When democracy is considered broadly, in which participation plays any role in decision-making or is being supported or bolstered or improved (or degraded) through technology, the following areas are all relevant: mass and social media, social movements, civic ignorance (or agnotology), political discussions, voices of minorities, gerrymandering, voter suppression, as well as the various technological threats, including the pernicious ones discussed above-and the more pernicious ones looming on the horizon. The background and contextual knowledge of democracy and technology might not always be immediately useful but best to keep in mind, as it should prove useful in evaluating and critiquing one's own work and the work of others and, essentially, being a citizen as we move forward into the future.

Technological (digital) integration extends far beyond developing new digital systems or automating existing non-digital systems. Deliberation, new media, policies to promote democracy and discourage non-democracy, and updated civic education are all part of this remit. Digital democracy could help usher in new and better forms of engagement and deliberative venues, but please also keep the non-digital elements of democracy in mind: The digital divide did not go away (contrary to conventional wisdom of the 1990s). The people without access to the technology (aside from those being denied loans, etc., through automated redlining [26]) still account for a non-trivial portion of the population in the United States and around the world and are typically people who are already marginalized through poverty, their geographical location, or other reasons. Also consider nondemocratic countries and other collectivities, such as civil society organizations and community groups, who may or may not govern themselves democratically.

Being skeptical about democracy and technology or acknowledging the widespread abuse of democratic ideals that technology has enabled does not mean being categorically against all proposed uses. On the contrary. The new technology still has the same basic opportunities and affordances that it did when electronic democracy was being considered in 1991 by Rheingold and company. Many exist in diminished forms, some have morphed into new forms, and others have emerged. The needs of individuals and individuals collectively communicating, engaging, and collaborating still exist. This means that the needs for community networks still exist. Many of us now know what maybe should have been obvious all along: that the design and management of these systems should not be conducted solely by corporations whose objectives are solely maximum profitability. This means that considering new ways outside today's for-profit social media to promote and sustain democratic systems needs to be part of this discussion. There are thousands of other projects to highlight. The Democracy Lab ${ }^{3}$ in Seattle that promotes civic tech via quarterly non-competitive hackathons and other support is one. Another is eLiberate $^{4}$, the online system that supports distributed meetings with the hoary, yet still in daily use by thousands of organizations, Roberts Rules of Order. The idea of re-establishing an Office of Technology Assessment (OTA), suggested by Richard Sclove, among others, is yet another. The United States formerly had such an office, which would inform the legislature about the opportunities and challenges of upcoming technology in a non-partisan way. Unfortunately, the legislature determined that this type of knowledge was not necessary. A skeptical person might well assume that they in future would get their information right from the horse's mouth, i.e., corporate lobbyists. At any rate, the idea of a crowd-sourced OTA perhaps building on the Wikipedia model could help educate the citizens of the world and quite possibly some legislators as well. Developing new ways of critiquing one's own work and the work of others could also be useful. Proposers of new amendments to current democratic approaches (formal and informal) should be able to provide plausible stories of why they think their new approach might or ought to be useful and also to think about how it could be co-opted and how misuse could possibly profit foes of democracy.

\footnotetext{
${ }^{3}$ democracylab.org.

${ }^{4}$ eliberate.publicsphereproject.org.

Digital Government: Research and Practice, Vol. 1, No. 1, Article 3. Publication date: January 2020.
} 
Overnight, in historic terms, the new technology has created a new class of mega-rich individuals who might laugh when they read about the internet dreams of old, the "equalizer" concept, for example, as their computers tirelessly comb through exabytes of personal data of millions of people. Some of the old dreams of meaningful dialogue with people from around the world to build on shared purpose for a common future also seem naive, especially in today's context of increased nationalism and xenophobia. But these are still worthwhile concepts to consider. The need for international communication and dialogue prompted my proposal for a World Citizen Parliament [27]. I subjected myself to possible accusations of naiveté for the purpose of developing a thought experiment that could potentially evolve into actual experiments, not because I believed an institution like this provided solutions to the world's problems.

The development of the internet and its uses has been shaped to some degree through greed, myopia, magical thinking, solutionism, individualism, and other approaches that in one way or another prohibited or tamped down democratic approaches in favor of convenience, consumption, profit, and surveillance. Ultimately, of course, there is nothing divinely ordained that says that ICT governance should be left to authoritarian governments, predatory companies, and organized crime. Focusing on democracy-what it actually could or should be-seems to acknowledge that this is not the case. Throttling back on some of the most dangerous forces is as important as improving the quality of democratic processes. Ronald Deibert has provided a good list of approaches to address part of the problems [3], including "independent agencies with the power to hold social networks accountable." He also calls for "a comprehensive strategy of long-term reform" that extends "from the personal to the political, from the local to the global" and includes "systems of public education with media literacy, ethics, civility, and tolerance at the foundation." One important insight to note here is that the variety of solutions needed are just that: a variety. Democracy is propelled and maintained in a thousand ways; some ways will be more influential but no one way will suffice. This means that an important part of what we do is think about how various efforts work together and how things scale.

The tech-enabled threats to democracy discussed in the fournal of Democracy section were scarcely imagined when the Whole Earth Review ran its pieces on electronic democracy in 1991. At the same time, I do not want to characterize those visionaries as naive. They envisioned bold concepts that were-and probably still are-viable. The technology has changed-unbelievably so-but the need for strong democracy and the sparks for imagining it still exist. It is a pity that these ideas have been marginalized for so long. The stakes are magnitudes higher today, and the environment for democracy is more precarious. There is an uphill battle facing those who favor democracy. Democracy is radical, critical, complex, and fragile. Sometimes it is resilient and even powerful. What shapes it takes in the future depends, of course, on what we do now.

\section{REFERENCES}

[1] Computer Professionals for Social Responsibility. 1993. Serving the Community: A Public-Interest Vision of the National Information Infrastructure. Computer Professionals for Social Responsibility, Palo Alto, CA.

[2] Howard Rheingold. 1991. The great equalizer. Whole Earth Rev. 71, 6 (1991), 95-104.

[3] DIAC. 1994. Developing an Equitable and Open Information Infrastructure. Hans Klein and Coralee Whitcomb (Eds.), CPSR, Palo Alto, CA.

[4] Douglas Schuler. 1996. New Community Networks: Wired for Change. Addison-Wesley.

[5] Ronald Deibert. 2019. The road to digital unfreedom: Three painful truths about social media. f. Democr. 30, 1 (2019), $25-39$.

[6] Xiao Qiang. 2019. The road to digital unfreedom: President xi's surveillance state. f. Democr. 30, 1 (2019), 53-67.

[7] Steven Feldstein. 2019. The road to digital unfreedom: How artificial intelligence is reshaping repression. F. Democr. 30, 1 (2019), 40-52.

[8] Scott Mainwaring and Fernando Bizzarro. 2019. The fates of third-wave democracies. F. Democr. 30, 1 (2019), 99-113.

[9] Hélène Landemore. 2012. Why the many are smarter than the few and why it matters. f. Publ. Delib. 8, 1 (2012), 7.

[10] Douglas Schuler. 2001. Cultivating society's civic intelligence: Patterns for a new 'world brain'. Inf. Commun. Soc. 4, 2 (2001), $157-181$.

[11] Jurgen Habermas. 1996. Civil society and the political public sphere. Between Facts and Norms 329-387.

[12] Niall McCarthy. 2018. The Best and Worst Countries for Democracy. Forbes. February 1. Retrieved from https://www.forbes.com/sites/ niallmccarthy/2018/02/01/the-best-and-worst-countries-for-democracy-infographic.

[13] Roberto Stefan Foa and Yascha Mounk. 2016. The democratic disconnect. f. Democr. 27, 3 (2016), 5-17.

[14] Robert Proctor and Londa Schiebinger (Eds). 2008. Agnotology: The Making and Unmaking of Ignorance. Stanford University Press. 
[15] Naomi Oreskes and Erik Conway. 2008. Challenging knowledge: How climate science became a victim of the cold war. In Agnotology: The Making and Unmaking of Ignorance, R. N. Proctor and L. Schiebinger (Eds.). Stanford University Press, Stanford, CA, 55-89.

[16] Jay Shambaugh and Ryan Nunn. 2017. Why wages aren't growing in America. Retrieved October 24, 2017 from https://hbr.org/2017/ 10/why-wages-arent-growing-in-america.

[17] Martin Gilens and Benjamin Page. 2014. Testing theories of American politics: Elites, interest groups, and average citizens. Perspect. Pol. 12, 3 (2014), 564-581.

[18] Danielle Allen. 1996. A schedule of boundaries: An exploration, launched from the water-clock, of athenian time. Greece Rome 43, 2 (1996), 157-168

[19] John Dewey. 2013. A Common Faith (2nd ed). Yale University Press.

[20] Benjamin Barber. 2003. Strong Democracy: Participatory Politics for a New Age. University of California Press.

[21] Xavier de Souza Briggs. 2008. Democracy as Problem Solving: Civic Capacity in Communities Across the Globe. MIT Press.

[22] Richard Sclove. 1995. Democracy and Technology. Guilford Press.

[23] John Dryzek, André Bächtiger, Simone Chambers, et al. 2019. The crisis of democracy and the science of deliberation. Science. 363,6432 (2019), 1144-1146.

[24] Hélène Landemore. 2013. Democratic Reason: Politics, Collective Intelligence, and the Rule of the Many. Princeton University Press.

[25] Anna De Liddo, Simon Buckingham Shum, and Mark Klein. 2014. Arguing on the Web for Social Innovation: Lightweight Tools and Analytics for Civic Engagement. Arguing the Web, 2.0 Workshop. Amsterdam. Retrieved July 2018 from https://www.slideshare.net/ AnnaDeLiddo1/arguing-ontheweb20-deliddoal.

[26] Virginia Eubanks. 2018. Automating Inequality: How High-tech Tools Profile, Police, and Punish the Poor. St. Martin's Press.

[27] Douglas Schuler. 2013. Creating the world citizen parliament. ACM Interact. XX, 3 (2013), 38-47.

Received April 2019; accepted July 2019

Digital Government: Research and Practice, Vol. 1, No. 1, Article 3. Publication date: January 2020. 